\title{
Finite element analysis, design and experiment on solid propellant motors with a stress reliever
}

\author{
J.T. Chen ${ }^{\mathrm{a}, *}$, S.-Y. Leu ${ }^{\mathrm{b}}$ \\ ${ }^{a}$ Department of Harbor and River Engineering, National Taiwan Ocean University, Keelung, Taiwan \\ ${ }^{\mathrm{b}}$ Department of Mechanical Engineering and Applied Mechanics, The University of Michigan, Ann Arbor, MI 48109, USA
}

\begin{abstract}
The results of an investigation on solid propellant motors with a stress reliever are presented. The thermal stress and strain of solid propellant motors during service life were analyzed by means of MSC/NASTRAN using eight-node HEXA solid elements. Three design cases of a stress reliever were considered to study its effects on the reduction of thermal response. On the other hand, two additional design cases, with an alternative free-flap design or without any thermal stress relief design, were also analyzed for comparison. Verification of the analysis results was accomplished by applying the nondestructive test (NDT) after three cycles of thermal loading. Good correlation existed between the computational and experimental results when the corresponding failure location and failure mode of the solid propellant were compared. Two important design criteria are established. One is the minimum outer diameter of the stress reliever, which dominates the hoop stress. The other is the maximum outer diameter of the stress reliever, which controls the axial normal stress. (C) 1998 Elsevier Science B.V. All rights reserved.
\end{abstract}

Keywords: Solid propellant motor; Stress reliever; P-groove; Accumulative damage; Finite element and MSC/NASTRAN

\section{Introduction}

During the last two decades, more and more attention has been paid to the design, manufacturing, and evaluation of solid propellant motors in order to meet service life and performance requirements. As a result, much progress has been made in shape design of solid propellants. Meanwhile, it is also recognized that aging studies are extremely necessary to predict the service life of solid propellants [1]. In addition, it is well known that the thermal response of solid propellant motors plays an important role in the mechanical aging of solid propellants [2]. Therefore, the

\footnotetext{
* Corresponding author.
} 
reduction of thermal response is one of the significant considerations in the design of solid propellant motors. Usually, thermal response is more critical around the dome area of a solid propellant motor due to the thermal constraint resulting from changes of the geometry and material property. In order to reduce thermal response during service life, three types of designs, to the best of the authors' knowledge, have been incorporated around the dome area of the solid propellant, namely, the free flap, stress reliever and P-groove designs as shown in Fig. 1. Obviously, all these three design options are meant to reduce thermal response by downsizing the thermal constraint on the solid propellant around the dome area. Nevertheless, due to the laborious processes involved in manufacturing the free flap design, the latter two design options are presently favored over the free flap design from the viewpoint of practical application. Accordingly, while the P-groove design was developed by the Hercules Company [3], the stress reliever design was employed in the rocket system shown in Fig. 2. However, even if they are assumed to have almost the same performance, it is a fact that the "P" shaped slot is empty in the P-groove design but is filled with PU (polyurethane form) material made of porous medium in the stress reliever design. Moreover, the P-groove design requires a special technique in the related mold release. On the other hand, determining the optimal design parameters of the stress reliever is not straightforward and requires numerical effort.

In this paper, finite element analysis is used to provide an effective design guide for a wide variety of practical stress reliever shapes. Meanwhile, the nondestructive test using the X-ray technique is employed to verify the design and the results of finite element analysis. Design criteria will be presented based on the numerical and experimental results.

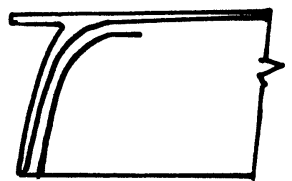

free flap design

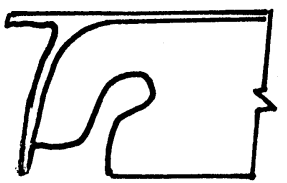

P Groove design

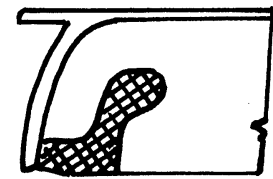

stress reliever design

Fig. 1. Three types of designs used to reduce the thermal response of the solid propellant motor: (a) free flap, (b) P-groove design and (c) stress reliever design.

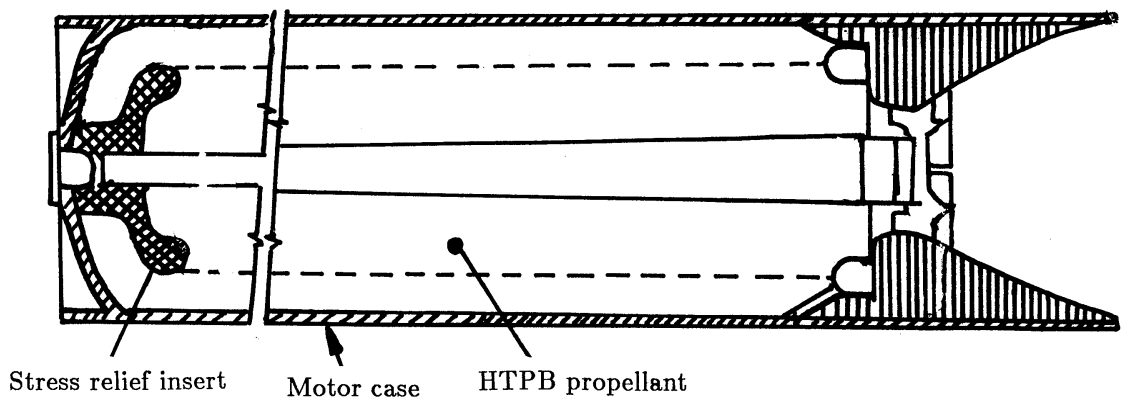

Fig. 2. The stress reliever design for the rocket system. 


\section{Statement of numerical task}

Finite element analysis was expected to provide results which are important for optimal stress reliever design. Three different design cases of stress relievers were evaluated. The effects of the three primary design parameters, namely, $L, d$, and $D$, as shown in Fig. 3, on the thermal response were investigated. As shown in Fig. 3, two additional design cases, with an alternative design employing a free-flap, located at the interface between the liner and propellant, or without any thermal stress relief design, were also considered for comparison. The above five design cases are called, respectively, type (a), type (b), type (c), type (d) and type (e), as shown in Fig. 4. The components of the solid propellant motor are those shown schematically in Fig. 2. The critical thermal environment is $-20^{\circ} \mathrm{C}$.

\section{Numerical simulation and calculation}

The numerical task was based on the JANNAF code [5]. Accordingly, the linear viscoelastic behavior of the solid propellant was simulated as quasi-elastic [7,8]. The solid propellant was the HTPB, and its stress free temperature was $70^{\circ} \mathrm{C}$. Therefore, the uniform, steady-state thermal loading considered on the solid propellant was $-90^{\circ} \mathrm{C}$ for the critical environment. In reality, the stress reliever is made of PU material; however, it could be treated numerically as an empty slot due to its insignificant thermal and mechanical properties, compared with those of the propellant.

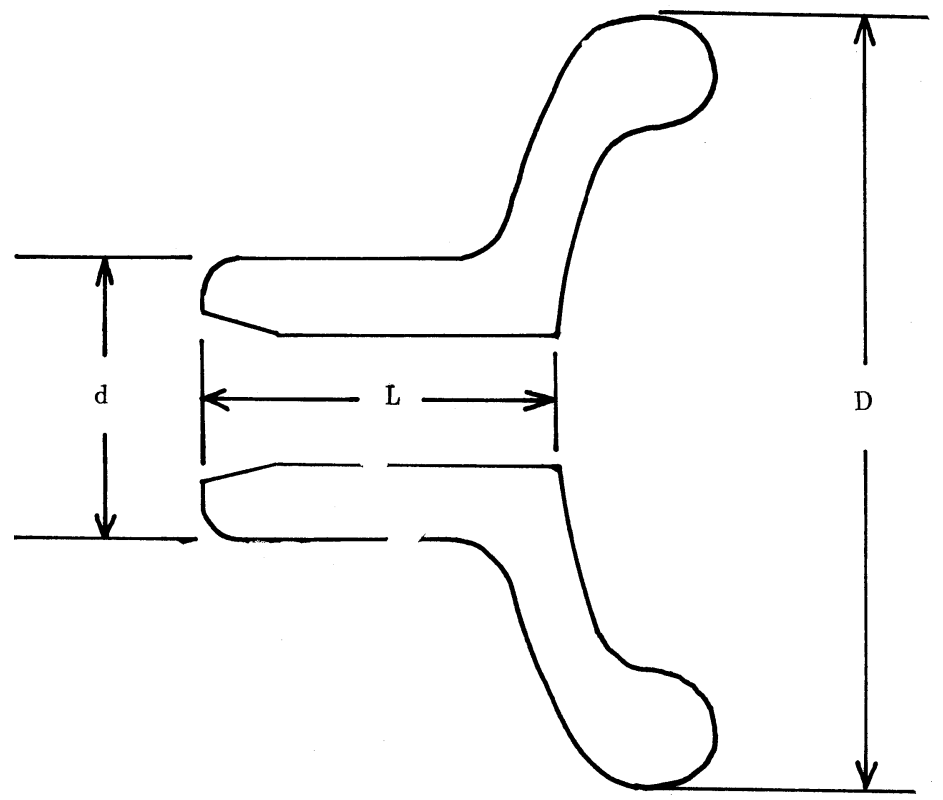

Fig. 3. The definition of the design parameters, $L, d$ and $D$. 
unit: $\mathrm{mm}$
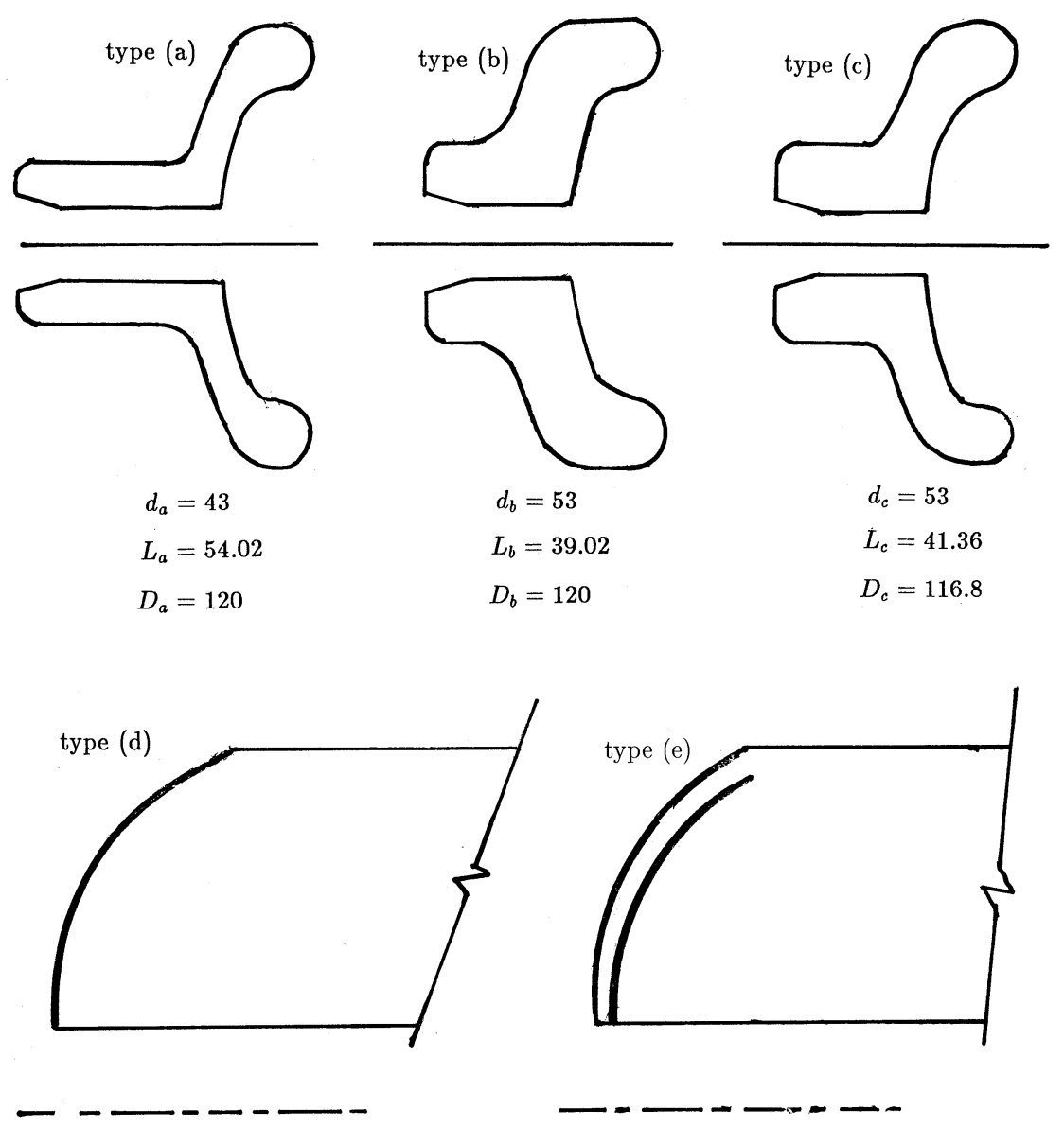

Fig. 4. The dimensions of the five design types.

The MSC/NASTRAN eight-node HEXA solid elements were used for the finite element analysis [11]. Due to the symmetry of the geometry and loading, a model of a five-degree axis-symmetric segment was used for simplicity without loss of accuracy. Some appropriate finite element mesh systems were built for the five design cases, respectively, to acquire their corresponding convergent results. The one for design type (b) is shown in Fig. 5. Reduced integration was adopted to simulate the nearly incompressible property of the solid propellant. A detail of finite element modelling can be found in [6]. For the numerical calculations, the material properties listed in Table 1 were required. Among them, the material properties of the solid propellant deserve detailed discussion as follows:

Solid propellant grain. The effective propellant modulus, $E$, is the value of the relaxation modulus acquired after some manipulation. Fig. 6 shows the relaxation modulus versus the temperaturereduced time. The temperature-reduced time, then, is the time required to reach equilibrium, $t^{*}$, 


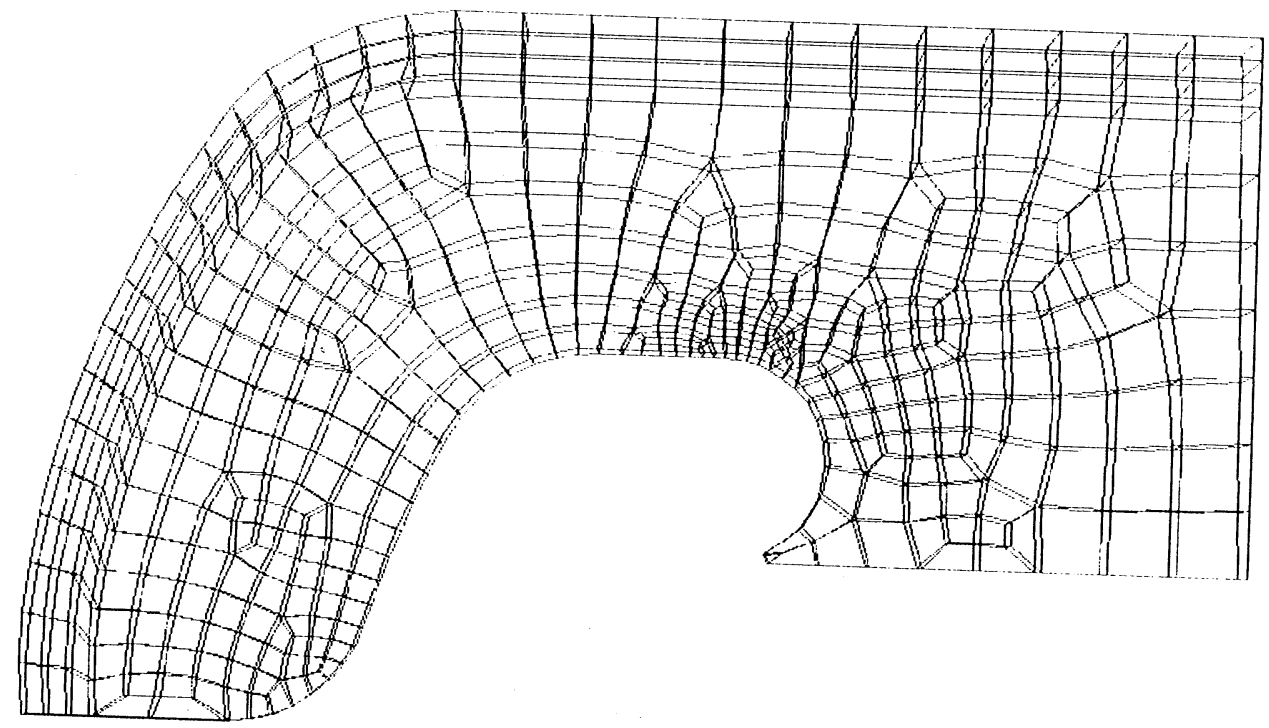

Fig. 5. Finite element mesh of design type (b).

Table 1

Material properties of the solid propellant motor

\begin{tabular}{llll}
\hline & Steel case & Insulator & Propellant \\
\hline Material & SAE4130 & I58 & HTPB \\
\hline Young's modulus $\left(\mathrm{kg} \mathrm{f} / \mathrm{cm}^{2}\right)$ & 20386 & 0.312 & 0.305 \\
Poisson ratio & 0.228 & 0.499 & 0.499 \\
Thermal expansion coefficient $\left(1 /{ }^{\circ} \mathrm{C}\right)$ & $1.07 \times 10^{-5}$ & $1.48 \times 10^{-4}$ & $6.645 \times 10^{-5}$ \\
Relaxation modulus curve & $\times$ & $\times$ & Fig. 6 \\
Time shift factor curve & $\times$ & $\times$ & Fig. 7 \\
\hline
\end{tabular}

defined by the shift factor, $a_{T}$, in Fig. 7. The relaxation modulus can be expressed as

$$
E=E\left(t^{*} / a_{T}\right) .
$$

The curves in Figs. 6 and 7 are plotted according to the experimental data in the environment under different temperatures.

The failure criterion for the solid propellant depends on its allowable stress and allowable strain. The strength of the propellant is obtained from the master allowable stress and strain curves in Figs. 8 and 9, as shown below:

$$
\begin{aligned}
\sigma_{\mathrm{a} 1} & =5.6 \mathrm{~kg} \mathrm{f} / \mathrm{cm}^{2}, \\
\varepsilon_{\mathrm{a} 1} & =23 \% .
\end{aligned}
$$




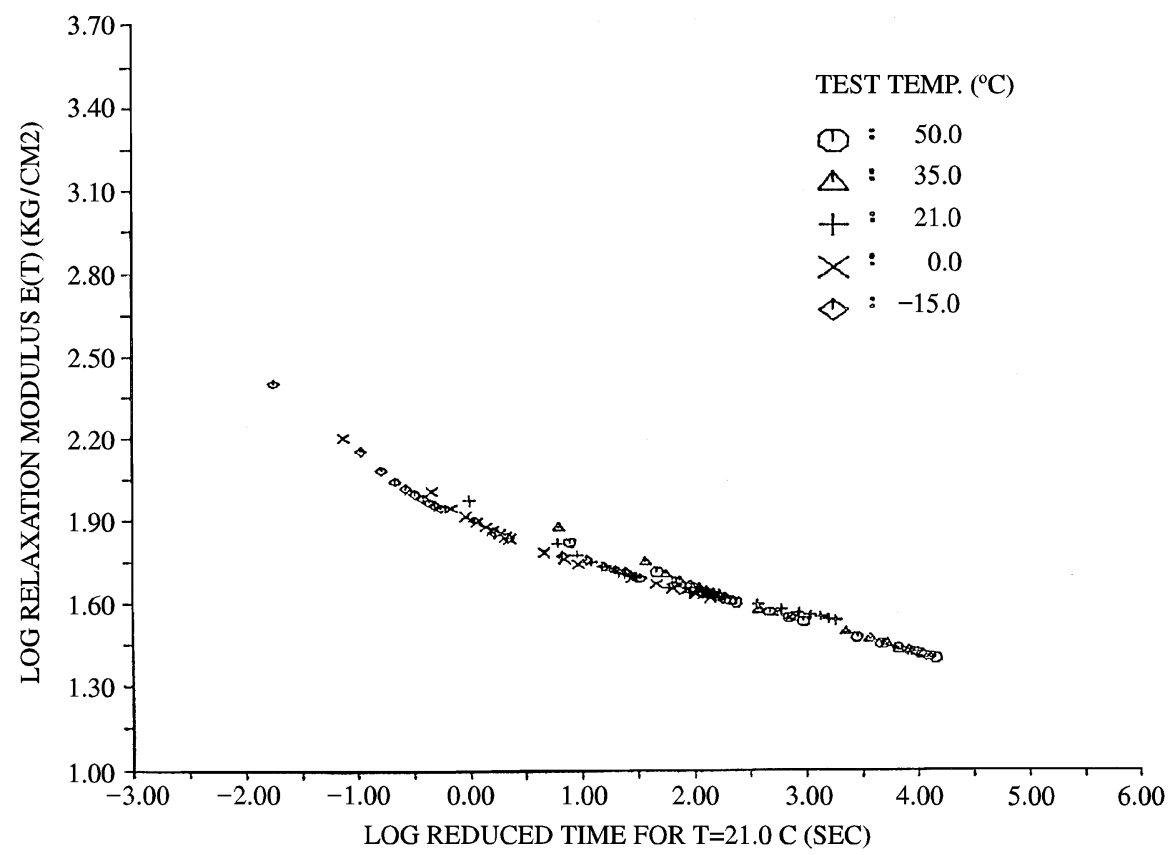

Fig. 6. Master curve of the relaxation modulus for the HTPB propellant.

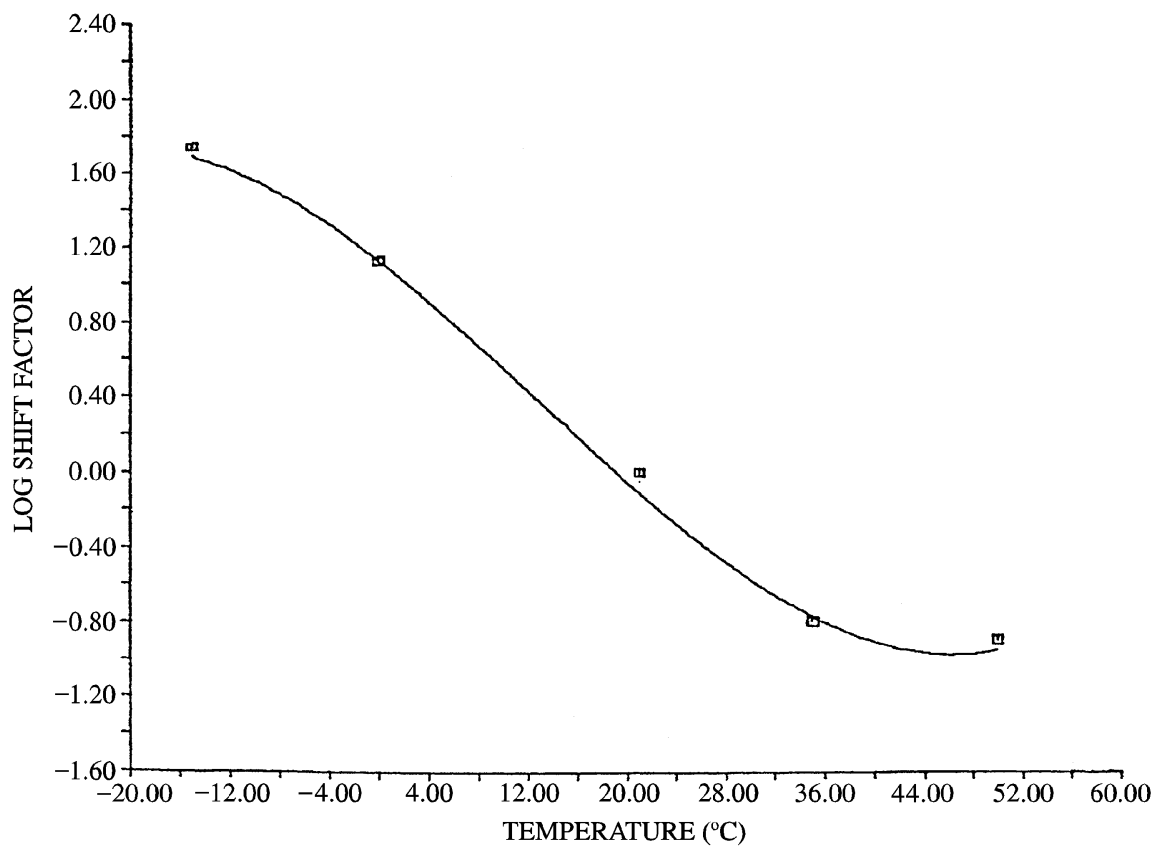

Fig. 7. Time-shift factor for the HTPB propellant. 


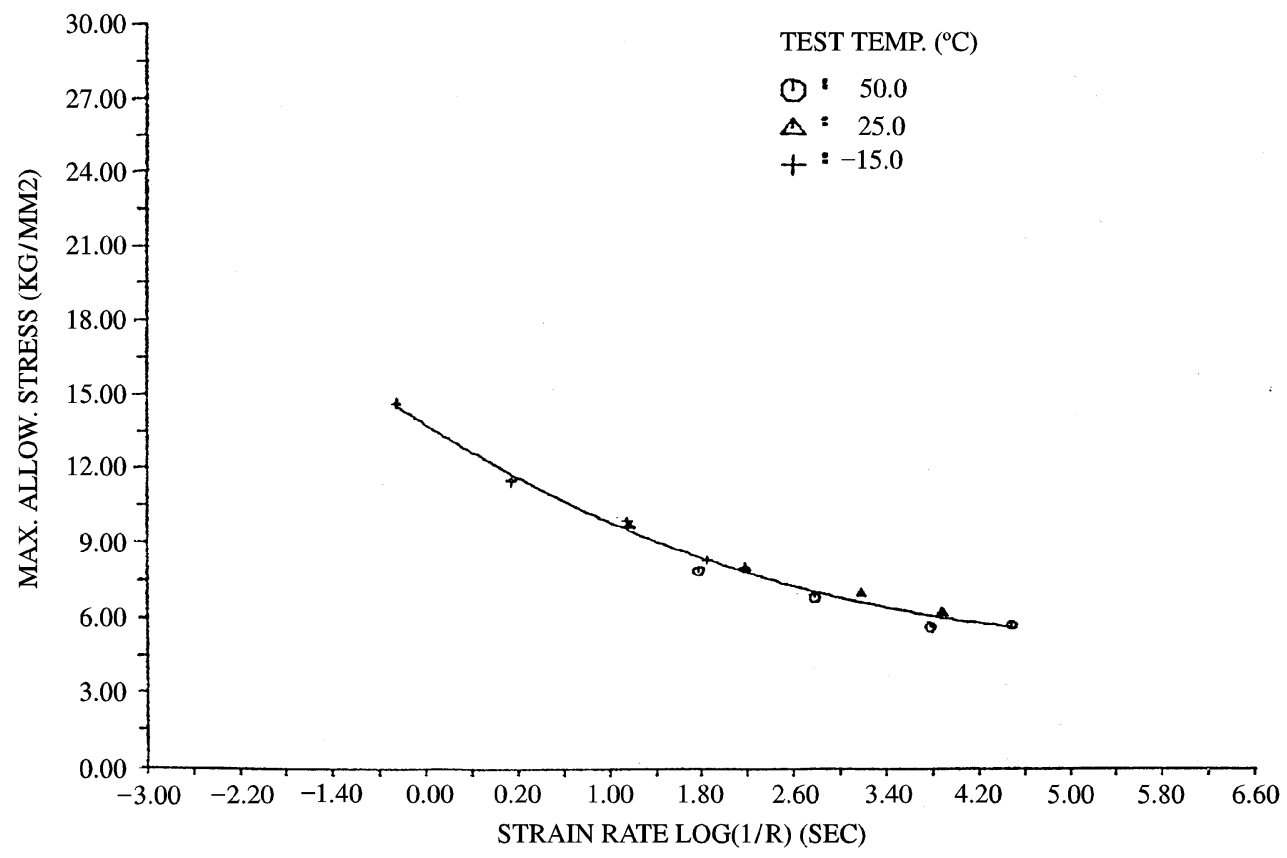

Fig. 8. Master curve of the allowable stress for the HTPB propellant.

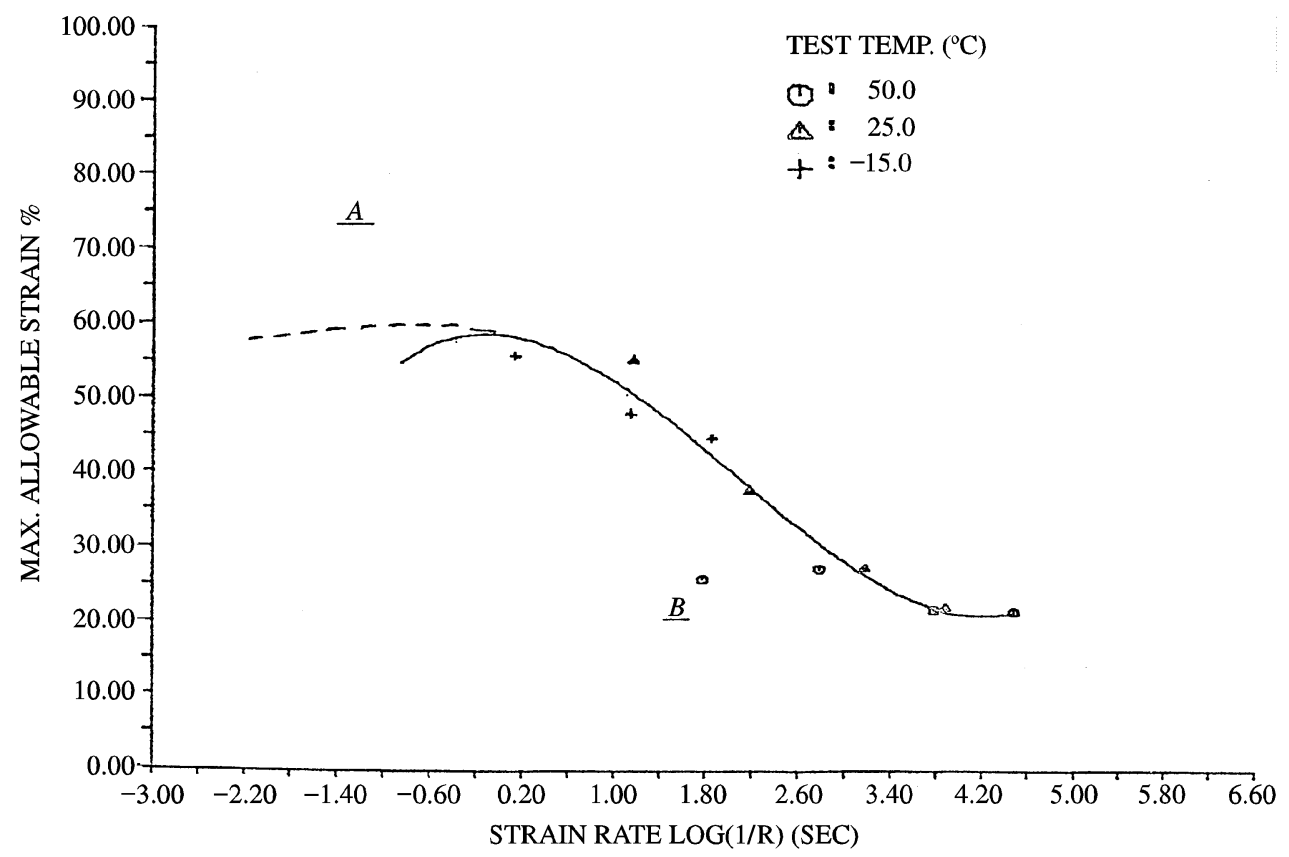

Fig. 9. Master curve of the allowable strain for the HTPB propellant. 


\section{Experimental verification of the finite element analysis}

A nondestructive test using the X-ray technique was utilized to verify both the design and numerical simulation. The experiment was performed after three cycles of thermal loading, as shown in Fig. 10, according to standard specifications [4] for solid propellant motors. Experimental results were used to confirm the failure location and failure mode predicted by means of computational effort.

\section{Results and discussions}

1. The numerical results of the five design types are summarized in Table 2. The maximum principal components of the stress and strain were calculated to evaluate the safety factor of the solid propellant. On the other hand, the computational deformation and stress distribution of the solid propellant of design type (a) were as shown in Figs. 11 and 12, respectively. With the inclusion of stress reliever, the axial stress $\left(\sigma_{z z}\right)$ was more critical than the hoop stress $\left(\sigma_{\theta \theta}\right)$ as shown in Table 3.

2. Based on the above numerical results, two critical areas, as shown in Fig. 12, were found to be possible locations of cracks when the safety factor was checked.

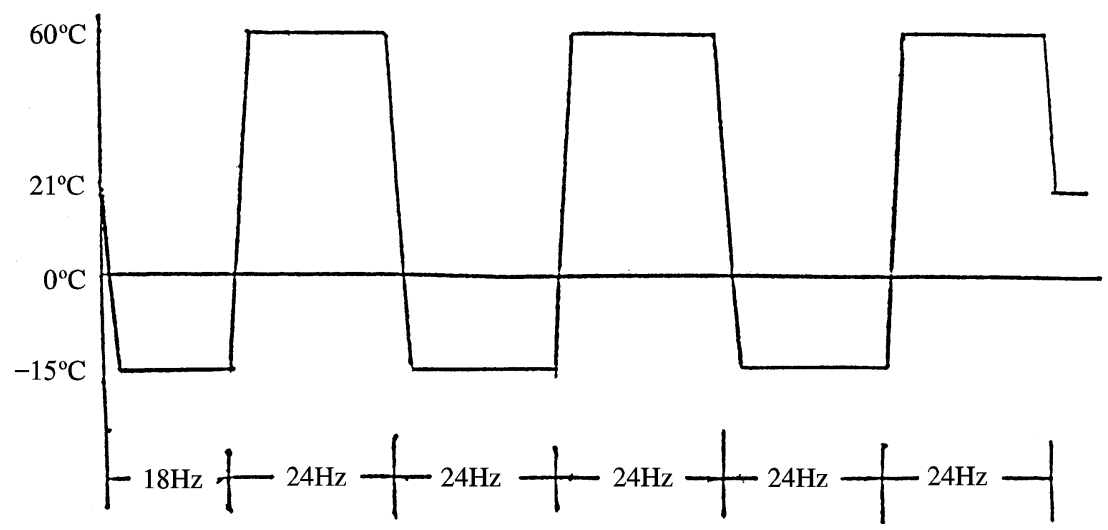

Fig. 10. Three-cycle thermal loading test for the solid propellant motor.

Table 2

The results of finite element analysis

\begin{tabular}{llllll}
\hline Type & (a) & (b) & (c) & (d) & (e) \\
\hline Max. displacement $(\mathrm{mm})$ & 2.28 & 0.99 & 0.747 & 3.01 & 2.02 \\
Max. principal stress $\left(\mathrm{kg} \mathrm{f} / \mathrm{cm}^{2}\right)$ & 1.59 & 1.22 & 1.18 & 1.38 & 1.28 \\
Max. principal strain (\%) & 5.41 & 3.51 & 2.63 & 3.23 & 4.91 \\
\hline
\end{tabular}




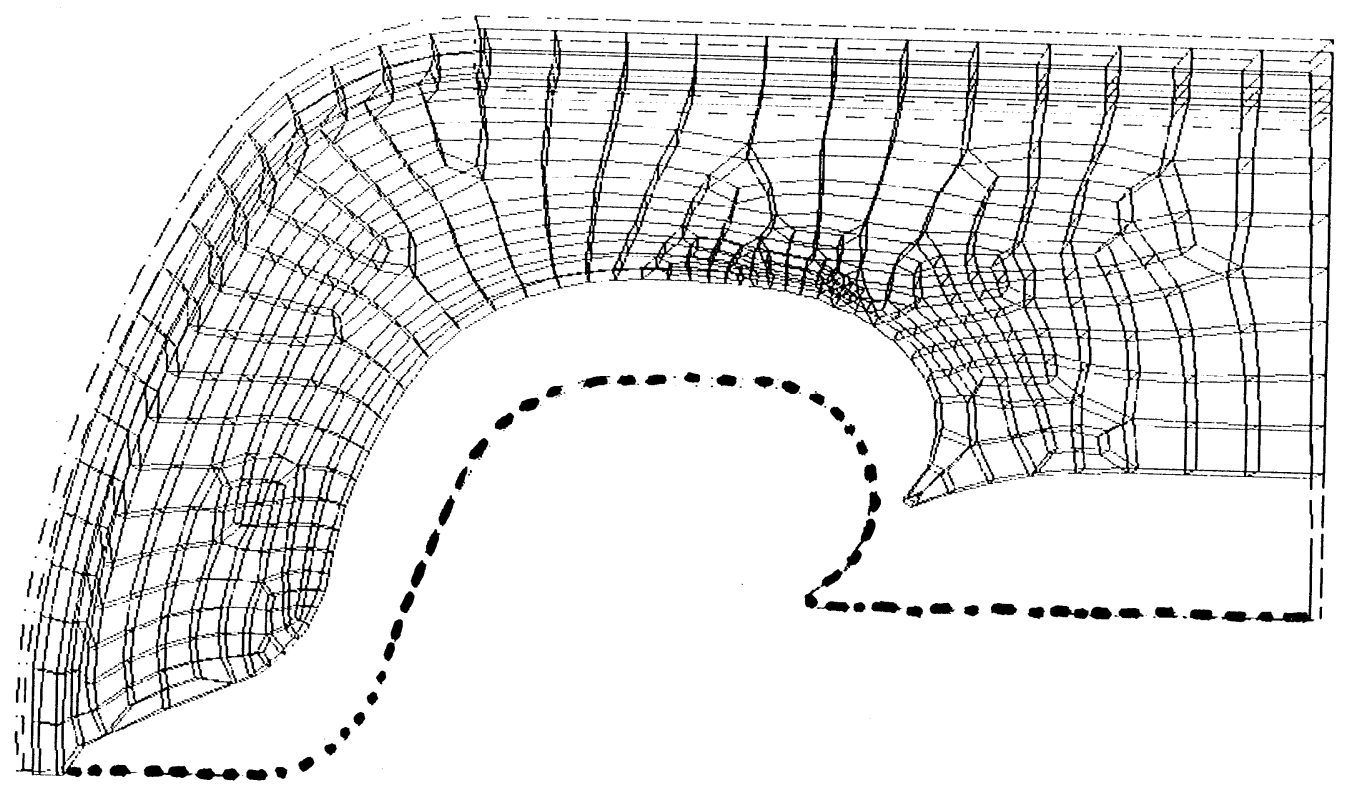

Fig. 11. Deformation of the type (b) motor under thermal loading.

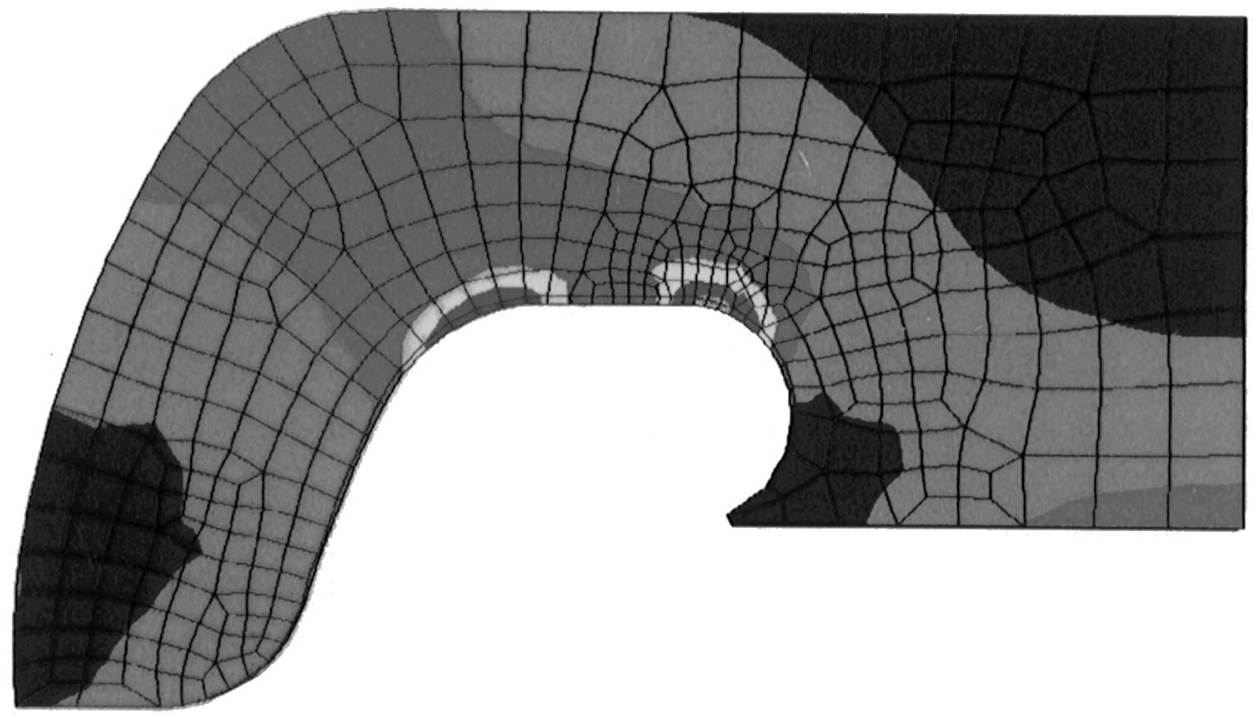

Fig. 12. Stress distribution of the type (b) motor under thermal loading.

3. The nondestructive test results for design type (b) were those as shown in Fig. 13. No crack was observed inside the solid propellant under the $-20^{\circ} \mathrm{C}$ temperature environment. However, two cracks appeared after the three cycles of thermal loading. The normal vectors of these crack surfaces were along the longitudinal direction of the solid propellant motor. This is caused by 
Table 3

Stress components of type (b) at the failure location

\begin{tabular}{lllll}
\hline Stress components & $\sigma_{1}$ & $\sigma_{z z}$ & $\sigma_{\theta \theta}$ & $\sigma_{r r}$ \\
\hline$\left(\mathrm{kg} \mathrm{f} / \mathrm{mm}^{2}\right)$ & 1.22 & 1.14 & 0.97 & 0.25 \\
\hline
\end{tabular}

Note: $\sigma_{1}$ is the maximum principal stress.

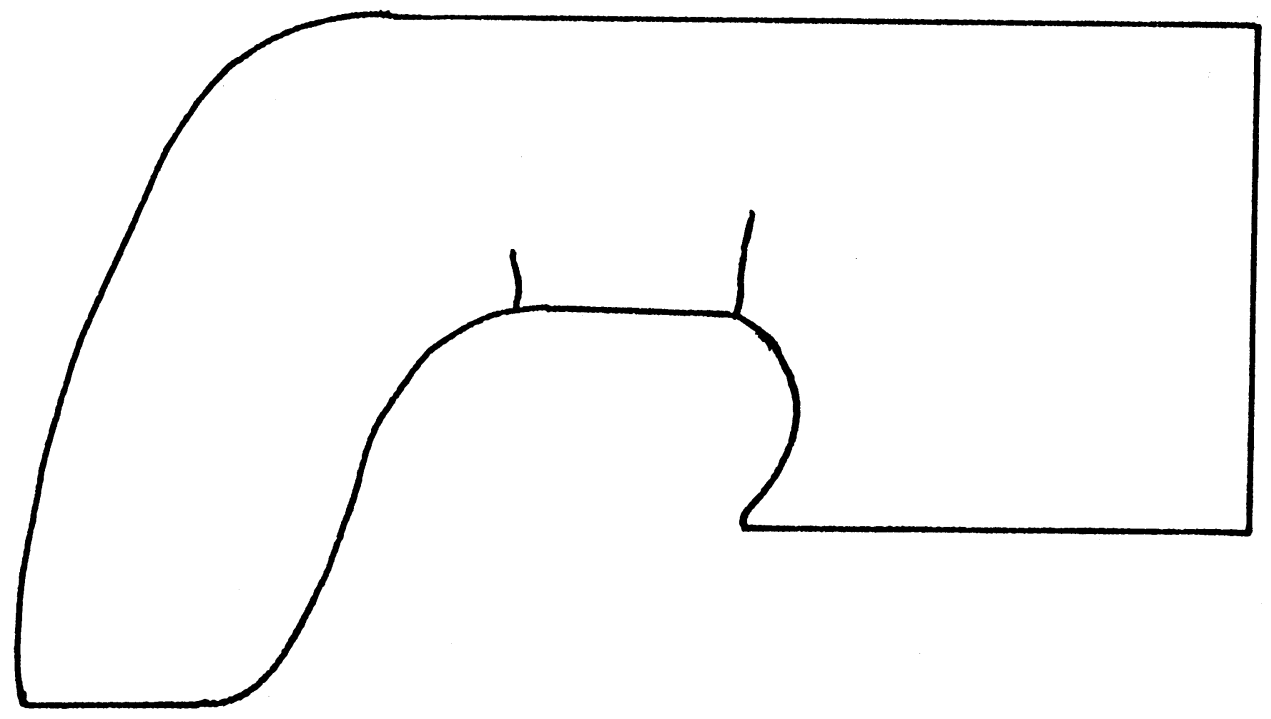

Fig. 13. NDT X-ray results of the type (b) motor after three-cycles of thermal loading.

the bending effect, which is due to thermal deformation as shown in Figs. 11 and 12. Also, Table 3 supports this idea since $\sigma_{z z}$ dominates.

4. The computational and experimental results agree very well for the failure mode and failure location of the solid propellant motor as shown in Figs. 12 and 13.

5. Comparing the results of design types (a)-(c), the effects of design parameters $L, d$ and $D$ on thermal response are clear. Parameter $D$ seemed to play a dominate role in reducing the thermal response. It controlled the failure mode induced by the axial stress or hoop stress. Accordingly, two important design criteria can be established. One is the minimum outer diameter of the stress reliever, which dominates the hoop stress. The other is the maximum outer diameter of the stress reliever which controls the axial normal stress. This is caused by the bending effect, which is due to thermal deformation since $\sigma_{z z}$ dominates as shown in Table 3 and Fig. 12.

6. Comparison of the computed results for the five design types shows that the appropriate stress reliever design is better than the free flap design in terms of reduction of the thermal response. 
However, poor design of the stress reliever will induce a worse thermal response compared to the thermal response of the propellant without any thermal stress relief design.

7. According to the Bill's model [2,9], the accumulative damage to solid propellants can be described as follows:

$$
D=\int_{0}^{\tau}\left(\frac{\sigma(t)}{\sigma_{t m}}\right)^{B} \mathrm{~d} t
$$

where $\sigma(t)$ is stress history, $\sigma_{t m}$ is material constant and the value of the exponential factor, $B$, is on the order of 6-16 for the HTPB propellant. Accordingly, the exponential effect clearly reveals the importance of thermal response reduction. Therefore, inclusion of an appropriate stress relief design is imperative to prevent premature cracks in the HTPB propellant; i.e., even a small reduction of thermal stress can lead to much longer service life [8-10].

8. The computational results were based on the uniform, steady-state thermal loading condition; however, the numerical evaluation was still reliable for design purposes. With the use of an appropriate safety factor, engineers can take into account the effects of the transient behavior and accumulative damage inherent in the three cycles of thermal loading.

9. Though the thermal and mechanical properties of the PU stress reliever are negligible compared with those of the solid propellant, the fracture toughness of the solid propellant may be degraded by the migration effect between the PU stress reliever and the solid propellant.

\section{Conclusions}

Some numerical results of the thermal response of a solid propellant motor have been implemented using MSC/NASTRAN. The numerical prediction of the failure mode and failure location of the solid propellant has been confirmed by NDT observation. In the numerical computation, the stress reliever was simplified into an empty slot. Due to the similarity of numerical simulations, the computational results are applicable to P-groove design. Two important design criteria have been established. Based on these criteria, it is possible to reduce the time and experience required for shape design.

\section{References}

[1] J.T. Chen, Review of service life prediction method of solid rocket motor, Sin-Sin J. C.S.I.S.T. 17 (1990) (in Chinese).

[2] J.T. Chen, C.Q. Lee, S.L. Lin, Application of cumulative damage to service life prediction of solid rocket motor, Sin-Sin J. C.S.I.S.T. 16 (1989) 155-163 (in Chinese).

[3] Private Communications with Dr. S.W. Beckwith, 1985.

[4] Military specification of rocket motors, Aeronautical, Qualification Test Program, MIL-R-25534A (USAF), 1956.

[5] JANNAF minimum standard structural analysis procedures for solid rocket grains under thermal and pressurization loadings, The Johns Hopkins Univ., 1987.

[6] J.T. Chen, S.L. Lin, C.Y. Chiou, S.W. Chyuan, J.Y. Hwang, W.R. Harn, W.T. Chin, Finite Element Analysis and Engineering Applications Using MSC/NASTRAN, Northern Gate Publ., Taipei, Taiwan, 1996 (in Chinese). 
[7] S.L. Lin, I.C. Tsai, N.C. Shieh, MSC/NASTRAN stress analysis application in linear viscoelastic material problem, The First Annual MSC/NASTRAN User's Conference, Taiwan, 1989 (in Chinese).

[8] MSC/NASTRAN Application Notes, Section 5, 1982, pp. 1-26.

[9] K.W. Bills, Structural design monogragh for thermal cycling of tactical rocket propellants, NWC TM 3365, 1978.

[10] R.A. Heller, M.P. Singh, Thermal storage life of solid propellant motors, J. Spacecraft 20 (1983).

[11] H.G. Schaffer, MSC/NASTRAN Primer-Static and Normal Modes Analysis, 3rd ed., Schaeffer Analysis Inc., 1979. 